\title{
IJTARP
}

\section{Supervision in Psychotherapy from the Perspective of Transactional Analysis}

\author{
(C) 2018 Maria Regina Ferreira Da Silva
}

This paper appeared originally in Portuguese as Supervisão em Psicoterapia na Perspectiva da Análise Transacional REBAT XIV, Aug 2015, 108-119 and is reproduced here by kind permission of UNATBRASIL - União Nacional de Analistas Transacionais - Brasil.

Where possible, quotations have been adjusted to reflect original English publications, particularly for TA publications.

\begin{abstract}
This article deals with supervision in clinical psychology that is distinct from pedagogical practice in psychology. The objective is to expand the reflection about supervision, the role of the supervisor and the training of psychotherapists from the perspective of supervision in the methodology of transactional analysis. Supervision is about a process of professional development that must qualify the skills of the trainee, develop those that are lacking and expand their potential to achieve professional success, since the construction of psychotherapeutic knowledge is not limited to theoretical content and must include training practical skills, professional posture and ethics.
\end{abstract}

\section{Keywords}

Transactional Analysis; Supervision; Psychotherapy; Psychology

\section{Introduction}

Newly qualified as a Teacher of the National Union of Transactional Analysts, supervising newly graduated students and student psychotherapists of transactional analysis, besides accumulating the position of guest professor at the Graduate School of Medical Sciences of Santa Casa de Misericórdia in São Paulo, for some time I have observed and reflected on the roles of supervisor and supervising. Having occupied the position of Director of Teaching and Certification of
UNAT-BRASIL, this interest led me to look for ways to improve the training of supervisors.

Supervision differs from clinical practice and pedagogical practice of psychology. Clinical practice focuses on diagnosis, intervention and cure. The pedagogic practice aims to acquire scientific and theoretical knowledge of psychology. Supervision is about a process of maturation and professional development.

Sakamoto (2006) considers that the core of supervision "is to meet the demands of the theoreticaltechnical integrations of clinical practice involved in attendance, the demands of the specific clinical practice of the approach adopted, and also helping the student in a professional training process with the acquisition of a professional identity "Supervision, therefore, can occur in two contexts: 1) supervision in clinical school - in psychology courses for students in their last years, and 2) supervision in university extension courses for trained professionals who want to acquire new techniques of psychotherapeutic approach or receive support to improve their professional performance.

The supervision exercised in the university context has as variables: the curricular grid, which limits the number of hours for the supervision process; the fact that it is the first experience of customer service by the student; the obligation to get credits, even for those students who are not interested in the clinical area; and the designation of the supervisor based on the teachers available. This teacher does not always have the profile and the interest necessary for this task, and sometimes, in the supervisory space, replicates the methodology of the classroom.

The student / psychotherapist has two main motivations: 1) the professional task of the clinical care of their patient, and 2) the integration of theory and technique that form the basis of professional identity. 
Supervision can also be exercised in the context of university extension courses: courses in psychoanalysis, cognitive-behavioural, transactional analysis, psychodrama and others. The variables that interfere here are the volunteer's choice as trainee, their experience as a trained psychologist, the desire to expand his knowledge, expand the scope of techniques, learn new theories and find support for difficulties in clinical practice. In this case, supervision is part of a tripod that characterizes the theoretical model of these courses' theoretical knowledge, psychotherapy and supervision. The supervisor, in this case, chooses supervision as a method of work, invested in their training, and is dedicated to developing and improving their competence in this area. This fact distinguishes them from the university professor, assigned to the role of supervisor.

Zaslavsky et al (2003) states that, in this context "supervision is a process of qualification of the candidate. In this sense, the supervisor's attitude should stimulate, in supervising, the development of his own abilities. One of the main functions of supervision is to develop in supervising the ability to perceive their own difficulties. This would be the way to achieve independence, following the learning process through self-criticism." (p.3)

In this context, supervision can be considered to be of a trainee who is in the process of training to acquire a new skill during the creation of identity in the role of psychotherapist. Therefore, I will use the word "training" as synonymous with "supervising".

I believe that the experience in the certification of transactional analysts of the National Union of Transactional Analysts - UNAT-BRAZIL, can contribute to the reflection on the role of the supervisor in the process of creating the professional identity of the psychotherapist.

\section{Psychotherapy Training - Eric Berne's Experience}

In the early 1960s in the USA, psychiatrist Eric Berne was responsible for training physicians residing at McAuley Hospital in San Francisco, California, proposing a training method that included: customer service, presentations and theoretical discussion in seminars and staff conferences.

Originally the psychotherapy group sessions conducted by Berne were attended in a mirrored room by resident physicians, until one day a schizophrenic patient in outbreak threw a chair breaking the mirror. Faced with this situation, Eric Berne invited the residents to participate as observers in the same room as the group. At the end of the psychotherapeutic work he asked patients to switch places with medical observers and proposed that residents, now in the centre of the group being watched by clients, would talk about what they had observed. The practice proved to be efficient, the resident doctors referred to clients with more objectivity and respect, and clients were interested in the discussion. Berne decided to include this proposal as a method of teaching in the hospital, conducting all team conferences in the presence of clients. He later included other staff members in the discussion, including nurses and social workers.

Berne considered that the therapist-client relationship should happen in an OK / OK basis which, in TA terms means that each have value and qualities independent of their roles; both are healthy and deserving of respect. If, on the one hand, the doctor / psychotherapist has privileged access to technical information, on the other, the client has privileged access to his / her history and the construction of his / her psychological process. This type of training method for residents and psychotherapists was not properly a model of supervision but was included as a working philosophy in the methodology of the processes of training transactional analysts of both ITAA and UNAT-BRASIL.

Creating the OK / OK space between client and psychotherapist, between supervisor and trainee; means generating a dialogical space of mutual respect and interest with a balance of power between the parties. The best way to build an OK / OK process of competence acquisition is through questions, as quoted by Andersen (1991):

"We consider that our contribution consists basically of questions, in particular those which our interlocutors generally do not ask themselves, and which give rise to many answers which, in turn, can generate new questions." (p.59)

The same author comments that a reflexive posture includes: the review of spontaneous and automatic response usually centred on certainty (judgment); personal investigation generating intrasubjective movement (thoughts, feelings); the construction of a collaborative context; and the transformation of the conversation into an external dialogue of internal dialogues in order to generate what he calls "dialogue of dialogues".

In the context of supervision, this posture requires the supervisor to listen to the trainee, to question the impact the supervision has, and to make room for feedback on the trainee's interventions. On the other hand, the trainee, when answering the supervisor's questions, may reflect on their certainties and uncertainties, find out the impact of their actions and what feelings are mobilized as a result. When the dialogue between supervisor and trainee happens in this way, both are enriched by the experience. The trainees appropriate their own knowledge and 
questions while the supervisor, instead of presenting themself as all knowing, places trainees in the position of asking the questions, thus helping the trainees find their own answers.

This attitude creates an environment conducive for the trainee to listen to the client: both within the case and the client's feedback on the psychotherapeutic procedure; to listen to themself in the role of psychotherapist, and to listen to feedback from supervisor or peers.

It is necessary to consider that both supervisor and trainee have backgrounds: their life experiences, maturity, needs and knowledge. The questioning of the premises behind statements and the deepening awareness of the motives that lead supervisor and trainee to choose certain positions, allow the revelation of the background that surrounds them. And both trainee and supervisor are affected by their backgrounds, as well as the personal and emotional issues underlying performance. The backgrounds of the supervisor and the trainee must be heard, respected and at the same time relaxed by dialogue, leaving the dangerous territory of a presumed knowledge that limits access to the acquisition of new learning or questioning.

The OK/OK posture, therefore, presupposes balanced participation and responsibility of the parties. It is important that the contract between them is clear, establishing the goals to be achieved, the method for attendance and supervision, and what is expected of the performance of supervisor and trainee, including the motivation, expectations and fantasies of both. When these premises are established from the beginning of the supervisor/trainee relationship, problems, difficulties and transference processes can be discussed and solved.

When creating the dialogical space and the balance of forces between supervisor and training, a plan of action that addresses the training needs of the trainee is urgently needed.

\section{Development Needs}

The opening to acquiring new skills occurs differently for each trainee. One must consider the motivation, the theoretical knowledge, the maturity and the stage of development for each. At each stage of learning, the trainee experiences different needs. This is similar to the stages of early childhood development, where specific skills are developed as the child deals with the learning opportunities that life naturally provides. Levin (1982) cites six stages of development that apply from child development to the acquisition of knowledge and new skills:

Phase 1: Being - The basis of our existence from birth to six months - development needs relate to existing and living, communicating what you need, trusting and having your needs met.

Phase 2: Doing - The world of sensations and action between six and eighteen months - development needs are about trusting others, learning that it is safe and wonderful to explore the world, believe in your intuition, be creative and active and get support for these activities.

Phase 3: Thinking - The domain of concepts - between eighteen months and three years - development needs are about thinking for oneself, solving problems, expressing and managing feelings, especially anger, initiating the process of individualization .

Phase 4: Identity - The continuous evolution of the self - between three and six years of age - development needs are about affirming one's own identity, acquiring information about the body, sex, roles, about the world, socializing, learning to deal with the consequences of their actions and separating fantasy from reality.

Phase 5: Becoming Skilled - The 'hows' and 'whys' of life - between six and 12 years - development needs refer to the act of learning new skills (without having to be perfect), learning from mistakes and being appropriate, testing your skills and comparing yourself to others, testing ideas and values between different families.

Phase 6: Integration - Creation and reproduction - from 12 to 18 years - development needs are about achieving a clear separation from the family, developing independence, integrating sexuality with your identity.

Of course, in each stage of development the human being faces situations that invite them to develop each skill. The first opportunity to acquire these skills occurs in childhood, but as in a spiral, each of these phases can be recycled into adulthood. The opportunity for recycling is naturally offered by life and its challenges.

The learning context is one such opportunity. When the necessary conditions, encouragement, and recognition are offered, the person quickly uses their skills to explore the new experience and acquire a suitable repertoire for their development.

\section{Supervision in a Developmental Context}

The supervisor, when considering these elements in the supervision process, is able to provide-a unique attention to each trainee, qualifying their development needs and offering them the stimulus necessary for their evolution. This can also be done within training groups.

An important element to consider is the quality of feedback from the supervisor to the trainee. Often, by 
focusing on the result, the supervisor points out faults and points to be corrected in the trainee's performance, promoting negative feedback. If this happens too often, the level of anxiety and resistance during the supervision process can become high.

Napper \& Newton (2000) applied the concept of Levin's Development Phases to student training. This model allows the supervisor to create a repertoire of stimuli and positive feedback that stimulate the motivation of the trainee and enable the balance between motivation and demand.

In Phase 1: Being - The basis of our existence In adult life, the trainee recycles this phase at the beginning of any new activity, whenever accepting a new challenge, as for example, the beginning of working as a psychotherapist.

According to Sakamoto (2006), the "apprentice" psychotherapist experiences "expectations about professional competence, fantasies, desires about impotent or omnipotent behaviours, anxiety about the new and unknown professional situation" (p.2).

Considering these needs can be very helpful to the supervisor, who can stimulate the trainee with "You're doing well", "You can ask me at any time", "You can use imagination, fantasies can help learning", "Go at your pace, you have time, you do not have to hurry. "

The supervisor should provide a predictable structure, focused on theoretical knowledge. Identify the strengths and weaknesses of the trainee, because the way in which they apply them in their practice creates a baseline from which future knowledge will be built. At this point, the supervisor is seen as a model and indicates the 'how-to' through case-discussion, roleplaying, pieces of therapy, providing a repertoire to be "copied" by the novice psychotherapist.

The supervisor should also be an OK / OK relationship model with the trainee. When, from the beginning, a safe dialogue space is created for the trainee to express their fears, insecurities, fantasies, in a climate of unconditional acceptance, in which any question is welcome, a trust bond is generated between supervisor and trainee. In a group, this posture creates the space to talk about personal experiences and exchange feedback with respect and security. When the trainee feels safe, they go naturally to Phase 2 and begins to explore the new world that opens up to them.

Phase 2: Doing - The world of sensations and action

The trainee begins to explore the new information, trying to put it into practice. Like a child who begins to crawl and broaden their experiences, the trainee wants to experience everything a little. The very act of exploring various situations is already gratifying, and there is still no clear enough relationship between theory and practice. Various flavours are experimented with, as well as looking a little at everything, getting to know and creating an image of this new world.

The needs of the trainee can be met by the supervisor with an attitude that involves statements such as "I like the way you ask questions", "You have creative and excellent ideas", "You make good correlations", "Let's build on what you have observed", "I encourage you to think about your ideas and experiences", "I will help you relate your experiences to theoretical references." This is the time to encourage the trainee to act, test their skills and knowledge. As the trainee gains some mastery of theory then the focus is on developing a sense of confidence, helping them feel comfortable and secure in the role of psychotherapist, recognizing and appropriating what they already know.

This can be achieved by encouraging the application of skills, help and positive reinforcement for what is being done. With the encouragement of the supervisor, the trainee can explore different types of techniques, procedures and attitudes, seek to relate theoretical knowledge to practice, locate and fill possible gaps in their studies, learn to describe the behaviours of the clients and relate them to diagnostic hypotheses, and to observe the results of their interventions. After much exploration, the trainee naturally begins to draw conclusions and to trust their own perception, moving to Phase 3 .

\section{Phase 3: Thinking - the domain of concepts} In adulthood, the trainee begins to master theoretical concepts, knows how to put them into practice, and needs to find their own method of doing things.

The needs of the trainee can be met by the supervisor in an attitude that involves statements such as "You work well with details", "You can think of a way to solve this problem", "What do you think of this?", "You have an excellent ability to think, "How do you feel about these thoughts?"

This is also a good time to begin analysing transference processes by asking the trainer about the feelings that affect them in their relationship with the client or with the supervisor or peers in the supervision group. It is important to learn to think about what they feel and also to perceive the feelings that arise from these thoughts.

Evaluation and feedback on results achieved and information on skills not yet acquired will be the basis for acquiring new knowledge. Helping the trainee to exercise their 'inner gaze', describing their contact with their own emotions, memories, beliefs and fantasies, while observing the client's behaviour and phenomenological experiences, and placing them in a theoretical context: "Now I am aware that you ... 
(external observation) "," Now I am aware that I ... (internal observation: feelings, fantasies, physical reactions) ".

Questions about what the trainee observes in the client, in them, in the supervisor and the dynamics between them may be important. It is common at this stage for the trainee to test their own ideas, seeming to oppose the supervisor's suggestions. This requires patience from and understanding by the supervisor, because the more space there is for different points of view, the faster the trainee can feel recognized in their own way of thinking, moving on to the next step.

\section{Phase 4: Identity - The Continual Evolution of the Self}

Here the trainee already possesses some mastery of theory, knows how to apply it and can observe themselves in the therapeutic process. At this stage, the goal is to build an identity as a psychotherapist, refine methodology and learn to do therapeutic planning.

The supervisor can stimulate the trainee by saying, "You can find out what happens as a result of your actions," "What would be your way of dealing with this situation?", "I like the way you risked doing this," "You're figuring out how to handle this information very well." It's time to invite the trainee to dare to do it their way.

It may be useful to work in a group at this time when the variety of possible responses for a given situation can be observed, discussing and evaluating the therapeutic process from new perspectives, observing the interventions performed and comparing success and points of resistance; giving and receiving feedback, valuing both positive and corrective aspects. As theoretical knowledge increases, one invests in planning the treatment and next steps, exploring other intervention options. The trainee should be encouraged to look at and learn from their mistakes.

Some questions that might help: "What would you do differently if you could repeat this therapy session?", "What will you do next time you work with this client?"

This is the time to work with countertransference, defined here as all the psychotherapist's reactions to the client, which are the result of unresolved conflicts of the therapist. It may include beliefs, reinforcement memories, expectations, and anticipations. The supervisor may suggest that the trainee go through a process of psychotherapy to work on their personal issues that are interfering with their objectivity as a psychotherapist.

One can also use the comparison between different approaches, authors or techniques to deal with a situation, discussing the pros and cons of each and valuing the background of the trainee. At that moment, valuing the individual response and highlighting the skills already acquired may be fundamental. It is a good time to encourage the trainee to share and compare their experience with other trainees, which gradually strengthens their confidence, leading them to the next phase.

\section{Phase 5: Becoming Skilled - The "hows" and "whys" of life}

In adulthood, the trainee needs to test self and-others, find out where they can go and where their limits are. These needs can be met by the supervisor in an attitude that involves statements such as "Trial and error is the best way to learn", "This test is just for you to have an idea of how you are going, not to define your skills or your ability," "What can you do to improve your performance? "

It is a good time to discuss values and ethics in the relationship with the client, with the peers, with multidisciplinary teams and with society. Skills and theoretical knowledge are already well established, and the supervisor can deepen the questioning about the reasons that led to the choice of a particular intervention and what it is expected to achieve. Evaluation of results and planning of future actions are the main topic to be addressed at that time.

Theoretical discussions are important so the trainee can explore new possibilities for action. To create dialogical space for the trainee to test opinions different from those of the supervisor and to be respected in their own uniqueness is fundamental. Critical analysis and new theoretical discoveries can be very interesting to arouse the taste in the trainee for scientific writing.

You can ask the trainee to summarize the supervision: "What was the problem presented?", "What did you learn from the client work and supervision?", "What did you learn about yourself?", "What can you do differently next time?"

Phase 6: Integration - Creation and reproduction The trainee at this stage needs to create independence and broaden their view on the different aspects of therapy. The supervisor can encourage them by saying, "I believe you can describe well what you do," "Tell me what and how you are doing.", "You are summarizing information/ideas brilliantly!"

Trainees should be given an opportunity to explore, experiment, and gradually develop a unique therapeutic style of their own.

Working in groups, you can establish something to be observed; each one speaks to an aspect that has not yet been mentioned; and in the end the trainee reports what they learned from the different observations. 
It is also possible to vary the topics to be discussed and, as far as possible, to begin to relate different approaches through a case study: a) The trainee should describe the problem based on behavioural observation, b) Analyse this observation through a theoretical approach, c) Raise a hypothesis about the client from this theory, d) Develop one or more interventions that are consistent with the theory and hypothesis raised, e) If the trainee goes well thus far, they may be challenged to examine the behaviour from other perspectives, and possible theoretical hypotheses and interventions.

The supervisor will then stimulate the discussion of the various possibilities for intervention. Advanced trainees may be asked to supervise other trainees, develop scientific research, or come up with new ideas.

At this point, it is necessary to prepare the trainee for the disconnection of both the supervisor and the protected environment of the supervision group. The moment of farewell comes when the trainees leave excited about what they have learned, able to think critically about their work and able to relate to colleagues with interest and respect.

\section{Conclusion}

There are several ways for the supervisor to stimulate the motivation of the trainee in the supervision process. In addition to aspects of theoretical knowledge, technical and ethical skills, the supervisor should also be aware of the ability of the future psychotherapist to self-develop, stimulating them according to the level of development, valuing the trainee's background and skills already acquired.
The quality of the supervisor-trainee relationship is critical to successful supervision and success in the practice of the psychotherapist. The art of asking and giving feedback can be precious tools in the supervisory process.

The supervisor should constantly invest in their own improvement, as much as they invest in the improvement of their trainees.

Maria Regina Ferreira Da Silva, Psychologist and Teaching Member UNAT-Brasil, can be contacted on mresil@terra.com.br

\section{References}

Andersen, T. (1991) Processos Reflexivos. Rio de Janeiro: Instituto Noos

Levin, Pamela (1982) The Cycle of Development

Transactional Analysis Journal 12:2 129-139

Napper, Rosemary \& Newton, Trudi (2000). Tacticstransactional analysis concepts for all trainers, teachers and tutors + insight into collaborative learning strategies Ipswich: TA Resources

Sakamoto, C. K. (2006) Foco e Estratégia de Supervisão Clínica em Psicoterapia Breve. Cadernos de Psicopedagogia, 6: 10 http://www.scielo.org no longer accessible online 21 December 2018

Zaslavsky, J., Nunes, M.L.T. \& Eizirik, C.L.A. Supervisão psicanalítica: revisão e uma proposta de sistematização. Revista de Psiquiatria do Rio Grande do Sul, v. 25, n. 2 http://www.scielo.org no longer accessible online 21 December 2018 